NBER WORKING PAPER SERIES

THE COVARIANCE STRUCTURE OF EARNINGS

AND INCOME, COMPENSATORY BEHAVIOR

AND ON-THE-JOB INVESTMENTS

\author{
J. R. Kear 1 \\ Working Paper No. 1747
}
NATIONAL BUREAU OF ECONOMIC RESEARCH 1050 Massachusetts Avenue
Cambridge, MA 02138
October 1985

Research support provided by National Science Foundation grant SES 8218799 and by the College of Social Science, Brigham Young University. The research reported here is part of the NBER's research programs in Development of the American Economy and Labor Studies. Any opinions expressed are those of the author and not those of the National Bureau of Economic Research. 


\section{The Covariance structure of Earnings and Income, Compensatory Behavior and \\ On-The-Job Investments}

\section{$\underline{\text { ABSTRACT }}$}

Observationally alike individuals who make different choices about on-the-job investments should have earnings profiles that differ in systematic ways. In particular, investments in nonspecific human capital should result in lower initial earnings but higher earnings growth rates. Human capital models of this sort admit testing, then, by examining the covariance between the level of earnings and the growth rate of earnings. This paper reports estimates of this covariance using the sample covariance among income observations across time for the same individuals. The sample covariances are drawn from the Utah Panel Data, a panel of some 16,000 households with income and wealth observations at various intervals over the period from 1850 to 1900. The parameter of interest is negative. This estimate is robust to various specifications of the model. I also reexamine earlier work by Lillard and Weiss and Hause, who use data on earnings, and conclude that there is strong support for the on-the-job investment hypothesis using data from three quite different sources covering different economies and different time periods.

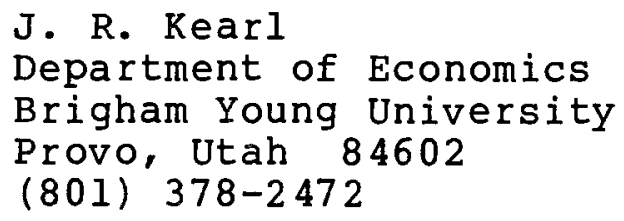


Age-related profiles in earnings or income are among the most robust regularities in economic data. However, the interpretation of these profiles in either cross sectional or longitudinal data is problematic. In a cross section, age and cohort effects are difficult to disentargle; in longitudinal data, age and economic growth effects are difficult to disentangle. Nevertheless, the inverted-U shape has usually been interpreted as reflecting growing individual productivity with experience and other kinds of investments in human capital, followed by the depreciation, obsolescence and declining physical and mental abilities that accompany aging.

Initial investment in human capital increases average earnings at any given age and may change the shape of the time related profile as wel1. For example, Mincer (1974) found a positive association between schooling attainment and the slope of the mean age-earnings profile and between schooling attainment and the length of time over which the profile has a positive slope.

In general, initial investments in human capital are thought to occur before employment, usually in a formal schooling environment or at home. Mincer $(1970,1974)$, however, has emphasized the investment possibilities that accompany the initial years in any occupation. It turns out that the on-the-job training opportunities provide a testable hypothesis about one aspect of the notion that individuals deliberately make investments in themselves. Tests of this "own" investment hypothesis using relationships between means were explored by Mincer. However, tests using individual data, which are more appropriate for the hypothesis, were developed and explored primarily by Hause (1977, 1980), 
Chamberlain (1978) and Lillard and Weiss (1979) (see also Borias and Mincer (1978)).

Tests using panel data are based on a compensatory notion: observationally equivalent individuals who choose different levels of on-the-job investment should have systematica?ly different individual time-related earnings or income profiles. More specifically, individuals who "invest" in generalized human capital will have lower initial earnings as they purchase capital (in the form of training) from their employers but will only make this investment if there is a compensatory increase in the rate of growth of their earnings over time. This implies that there should be a negative covariance between early earnings and the slope of an individual's earnings profile. Differences in earnings among individuals will be determined, then, by individual differences in the level of earnings and individual differences in the growth of earnings.

However, the test is not quite as clear-cut as this suggests since individual differences in earnings may also reflect differences in observationally-alike individuals that have nothing to do with on-the-job investments and everything to do with ability, individual values, cultural values and other differences that distinguish individuals but which are difficult to observe and measure. In this case, earnings differences would reflect permanent differences among individuals that persisted through time. A negative covariance between initial earnings and the slope of an earnings profile is consistent with on-the-job investment in human capital but it may also be that individuals with lower initial earnings simply work harder and that there is a negative covariance between initial earnings and subsequent 
effort. It may also be, of course, that higher ability is reflected both in initial earnings and in the growth of earnings so that there is a positive covariance between initial earnings and earnings' growth reflecting the consequences of underlying ability differences.

Thus, while a negative covariance may reflect things in addition to choices about on-the-job investments, a positive covariance between the level of earnings and the growth rate in earnings would be a clear refutation of a compensatory behavioral model.

Possible compensatory individual earnings profiles are also important because they imply that the cross-sectional variance in earnings or income, a measure of "inequality," reflects different choices made by otherwise similar individuals as well as stochastic elements and persistent individual dissimilarities. This gives rise to the much debated issue of measuring the "true" inequality in a population where the measured inequality using observable earnings or income does not reflect (generally overestimating) actual disparities in economic position. That is, compensatory profiles imply a lower variance in lifetime earnings than in annual earnings.

Whatever its limitations, a compensatory model of individual earnings is an appealing explanation of the age or experience-related pattern in earnings and important in our understanding of the underlying distributional dynamics in an economy. Despite the appeal of the covariance test, the empirical evidence is mixed. Mincer could not directly test the hypothesis since his data only allowed for comparisions of means. However, he found that for less schooled groups, there exists a longer initial period during which persons with greater earnings growth have lower earnings. In another indirect test, Borjas 
and Mincer conclude that individuals who make larger investments have lower initial earnings which, in turn, grow more rapidly than others. Similarly, Lillard (1977) found that both the more able and the more schooled were compensated by more rapidly rising earnings and by higher earnings later in their lives. Hause (1977) provides an indirect test using Swedish data. He found substantial systematic dispersion in earnings profiles for workers of the same age when education is factored out. He also found that discounted lifetime earnings had a substantially lower variance than did annual earnings (Lillard's analysis also supports this conclusion).

Chamberlain (1978), in a paper primarily focused on the biases in estimating returns to education, found a substantial variance in the growth rates of individual earnings and a large negative correlation between initial earnings and subsequence growth rates.

In later work, Hause and Lillard and Weiss directly confronted the possibilities of individual compensatory behavior. Hause (1980) used the sample covariance of earnings obtainable from Swedish panel data to estimate directly the covariance between initial earnings and earnings growth. The estimated model suggests that the on-the-job investment hypothesis is an empirically significant phenomenon. The data exhibit a negative covariance between the level of individual earnings and the slope of individual earnings profiles. The sign of this critical covariance is robust to a variety of specifications with complex error generating mechanisms. However, statistical significance is not robust and the variance of the individual slopes is small, indicating that the sample is quite homogeneous. In addition, the models of the error process that generate statistical significance for the covariance 
between slopes and intercepts have serious problems elsewhere that make them less credible.

Lillard and Weiss (1979' provide evidence from a panel of scientists that is not consistent with the on-the-job training hypothesis. When the effects of observed characteristics on earnings are controlled for, there is a positive correlation between the level of individual earnings (intercepts) and the growth rate of the individual earnings profiles (slopes). As Lillard and Weiss note "(t)he positive covariance between the level and growth error components indicates that for scientists who are observationally alike, high average earnings is associated with high growth. .." (page 445).

Since differences in the level and growth of earnings could arise either because of ability differences which increase both initial earnings and growth rates or because of investment patterns that tend to lower initial earnings while raising the subsequent growth rate, Lillard and Weiss speculate that for scientists, ability differences drive the observed relationship between initial earnings and subsequent growth rates instead of compensatory behavior. They conclude: "We find diverging earnings development over the decade among observationally alike individuals. That is, individuals with greater mean earnings also had greater earnings growth" ( $p$ 437).

It turns out that computational errors apparently lead to the wrong sign on the crucial parameter in the Lillard and Weiss analysis. Reestimating their model, using the residual variance-covariance matrix published with their paper, provides evidence that is consistent. with an on-the-job investment or compensatory model and to conclusions quite different from those noted ahove. Indeed, there is strong evidence that 
the covariance is negative and mostly unaffected by the problems associated with modelling the error process in data used by Hause and by Lillard and Weiss. Section II deals with these issues.

I provide additional evidence about the covariance structure of earnings and income by examining data from a auite different era, the 19 th century, in which on-the-job training is likely to be relatively quite important since formal schooling was less widespread than it is today. Following the specification of an error components model suitable for testing the relationship between the level of individual income and subsequent individual growth rates (Section I), I provide tests of a simple model in Section III. Since most of the previous work has been done with data sets of fairly short duration and the data that I use extends over the lifetime of many of the individuals in the sample, I then provide estimates of a more complex model that allows us to examine more of the age-income profile and, in particular, what happens to individual profiles past the typical peak in the inverted $U$.

\section{Compensatory Behavior and the Covariance of Earnings}

We assume that the aggregate or mean age-earnings pattern (what Hause (1980) calls the coarse structure of earnings) can be described by a regression of the logarithm of earnings on a quadratic in age, $g(A, B)$, with intercept differences depending upon observed individual characteristics, $f(C, B)$, such as occupation, gender, place of birth, etc,

(1) $\ln y_{i t}=f(C, B)+g(A, B)+u_{i t}$,

where $i, i=1, N$, indexes observations on individuals, $t, t=1, T$, indexes observations through time and $B$ is a vector of parameters.

This coarse structure, developed first by Ben-Porath (1967), has been explored extensively by Mincer (1974) and many others. Elsewhere 
we have examined age-income and age-wealth profiles more carefully using data from the Utah Panel and have examined possible interactions between individual characteristics and age and nonlinearities in age that are not allowed for with a simple quadratic specification (Kearl and Pope, 1984a, 1984b and 1985).

What Hause (1980) calls the fine structure of earnings is embodied in the specification of the structure of $u$. For example, if we allow for individual error components $\left(\delta_{j}\right)$ and individual time dependent error components $\left(\xi_{i}\right)$ plus a purely random error $\left(\nu_{i t}\right)$,

(2) $u_{i t}=\delta_{i}+\xi_{j}(t-1)+v_{i t}$.

The error structure for a sample with observations through time on the same individuals would be,

$$
\text { (3) } \begin{aligned}
u_{i 1} & =\delta_{i}+v_{i t} \\
y_{i 2} & =\delta_{i}+\xi_{i}+v_{i t} \\
y_{i 3} & =\delta_{i}+2 \xi_{i}+v_{i t} \\
y_{i 4} & =\delta_{i}+3 \xi_{i}+v_{i t} \\
y_{i 5} & =\delta_{i}+4 \xi_{i}+v_{i t}
\end{aligned}
$$

with corresponding variance-covariance structure,

$$
\begin{aligned}
& \text { (4) } \sigma_{\delta}^{2}+\sigma_{v_{1}}^{2} \\
& \sigma_{\delta}^{?}+\sigma_{\delta \xi} \quad \sigma_{\delta}^{2}+\sigma_{\xi}^{2} 2 \sigma_{\delta \xi}+\sigma_{v_{2}}^{2} \\
& \sigma_{\delta}^{2}+2 \sigma_{\delta \xi} \quad \sigma_{\delta}^{2}+2 \sigma_{\xi}^{2}+3 \sigma \delta_{\xi} \quad \sigma_{\delta}^{2}+4 \sigma_{\xi}^{2}+4 \sigma_{\delta \xi}+\sigma_{\nu_{3}}^{2} \\
& \sigma_{\delta}^{2}+3 \sigma_{\delta \xi} \quad \sigma_{\delta}^{2}+3 \sigma_{\xi}^{2}+4 \sigma \delta_{\xi} \quad \sigma_{\delta}^{2}+6 \sigma_{\xi}^{2}+5 \sigma_{\delta \xi} \quad \sigma_{\delta}^{2}+9 \sigma_{\xi}^{2}+6 \sigma_{\delta \xi}+\sigma_{v_{4}}^{2}
\end{aligned}
$$


assuming that

(5) $\sigma_{v_{i t} \xi_{i}}=\sigma_{v_{i t} \delta_{i}}=0$.

Then, if $S$ is the sample variance-covariance matrix and

(6) $\sigma_{v_{1}}^{2}=\sigma_{v_{2}}^{2}=\sigma_{v_{3}}^{2}$

the model can be estimated with a panel having three or more observations on each individual. For example, if $T=3$,

(7) $\partial_{\delta \xi}=S_{13}-S_{12}$

is identified and

(8) $\partial_{\xi}^{2}=S_{22}-S_{11}-2 \theta_{\delta \xi}=\left(S_{33}-S_{11}-4 \partial_{\delta \xi}\right) / 4$

is overidentified. The individual time-invariant variance component is

(9) $\theta_{\delta}^{2}=S_{23}-2 \partial_{\xi}^{2}-3 \theta_{\delta \xi}$

and the truly random component is also overidentified

(10) $\partial_{\nu}^{2}=S_{11}-\partial_{\delta}^{2}=S_{22}-\partial_{\delta}^{2}-\partial_{\xi}^{2}-2 \hat{\sigma}_{\delta \xi}=S_{33}-\partial^{2}-4 \partial_{\xi}^{2}-4 \theta_{\delta \xi}$.

The model remains identified if

(11) $\partial_{v_{1}}^{2} \neq \partial_{v_{2}}^{2} \neq \partial_{v_{3}}^{2}$.

This simple model is not identified with a two-observation panel since there are four parameters $\left(\sigma_{\delta}^{2}, \sigma_{\xi}^{2}, \sigma_{\delta \xi}, \sigma_{\nu}^{2}\right)$ but only three independent pieces of information $\left(S_{11}, S_{12}, S_{22}\right)$.

With at least three observations on each individual, some of the parameters are overidentified since there are now at least six independent pieces of information about the covariance structure, $\left(S_{11}, S_{22}, S_{33}, S_{12}, S_{13}, S_{23}, . ..\right)$. This allows for a richer specification of the covariance structure or for a more complex structure for "it. Lillard and Weiss (1979), Hause (1980) and Chamberlain (1978) have all estimated models with more complex structures for $v_{i t}$. Lillard and Weiss estimate a first order 
autoregressive model where the uncorrelated random element is drawn from a distribution with constant variance through time. Hause estimates a model with a non-stationary autoregressive structure where the period by period innovations have independent or time-varying variances. Chamberlain assumes time-invariant variances for the random element but estimates a more complex two-factor model with time varying parameters (or heterogeneity) which he interprets to be the time-varying shadow prices of unobserved individual characteristics.

The structure of $v_{i t}$ poses a probiem in ali the empirical results, including our own. As we note below, models with time-varying error variances, that is, where

(12) $v_{i t} \sim f\left(0, \sigma_{t}^{2}\right)$

dominate models where the error variance is assumed to be drawn from a distribution with a constant variance across time. However, there is no clear pattern in the error variances and hence, no easily generalizable observations.

Since complex structures for $v_{i t}$ are mostly uninformative, it seems useful to consider a richer specification of the "behavioral" part of the unobservable. Chamberlain's two-factor model is one approach. Within a variance components structure, we consider a model that allows for a more complete individual life cycle by allowing for curvature, (13) $u_{i t}=\delta_{i}+\xi_{j}(t-1)+\alpha_{j}(t-1)^{2}+v_{i t}$.

This model, with seven possible parameters, $\left(\sigma_{\delta}^{2}, \sigma_{\xi}^{2}, \sigma_{\alpha}^{2}, \sigma_{\delta \xi}, \sigma_{\xi \alpha}\right.$, and $\sigma_{\nu}^{2}$ ), is identified with a panel having four or more observations on each household.

In a simple model with level and slope effects, one can easily 
solve for the point at which the variance is minimized. The value of $t$ that minimizes the variance of $\delta_{i}+\xi_{i}(+-1)$, (14) $\sigma_{\delta}^{3}+2(t-1) \sigma_{\delta \xi}+(t-1)^{2} \sigma_{\xi}^{2}$, is

$$
\text { (15) } t_{\text {min }}=-\sigma_{\delta \xi} / \sigma_{\xi}^{2} \text {. }
$$

If observationally alike individuals make different on-the-job investments, their respective individual age- (or experience-) earnings profiles must cross. While there is no reason that the individual profiles for a population should cross at the same point, Mincer derives an upper bound for the crossover or "overtaking" point of $1 / r$, where $r$ is the return to on-the-job investments. The importance of the "overtaking" point or region is that it provides a closer estimate to the underlying inequality associated with individual differences that are not the outcome of individual choices. That is, if all profiles did cross at the same point, the variance in earnings at that point would reflect persistent individual differences that are not related to individual intertemporal choices about investment in earning potential. $\sigma_{\delta}^{2}$ is biased upward as a measure of such inequality because part of the variance is attributable to compensatory choices that individuals make.

Hause provides an argument for $t_{\min }$ as the lower bound for the "overtaking" point when ability cannot be directly measured and when the random component, $v_{i t}$, is drawn from a stationary distribution.

\section{Estimates from Hause and Lillard and Weiss}

Papers by Hause (1980) and Lillard and Weiss (1979) are the most ambitious efforts to estimate models that allow for compensatory 
behavior. Hause estimates a covariance structure for log earnings but does not have observations on individual characteristics and cannot estimate the covariance structure of the residuals, that is, his results of earnings less the effects of observed individual characteristics weakly support the compensatory hypothesis. Lillard and Weiss estimate the covariance structure for $\log$ earnings and for the residuals from a regression of log earnings on observed individual characteristics. Their results are inconsistent with the compensatory hypothes is since the covariance between the level and growth rate of earnings is positive.

Columns 6 and 7 of Table I partially reproduce Hause's estimates. (A11 of the reported covariance models are estimated with maximum likelihood techniques using LISREL.) The asymptotic $x^{2}$ statistic tests the specified model as the null hypothesis against the hypothesis that the sample variance-covariance matrix is any positive definite matrix of the same dimensions. While the null hypothesis is often rejected, differences in $\chi^{2}$ statistics are sometimes useful for comparing models. Joreskog and Sorbom (1980) show that for nested models, the difference between the asymptotic $x^{2}$ of the models is itself asymptotically $x^{2}$ with degrees of freedom equal to the difference between the degrees of freedom of the two models.

When Hause allows for a complex error structure, where each period's error is drawn from a distribution with time-varying variances and where there is a period-specific autocorrelation (column 6 , reproduced from Hause without the autocorrelation estimates), none of the parameters of interest are significant. The covariance between the initial earnings, $\delta_{i}$, and earnings growth, $\xi_{j}, \sigma_{\delta \xi}$, has a negative sign 
$(-.00245)$ but a standard error that is nearly 50 percent larger than the coefficient.

A Tess complex error structure, with a constant autocorrelation across time and only the first period's error drawn from a distribution with a different variance than the remaining five periods, produces parameter estimates for the variance components that are substantially larger than their standard errors and of a sign consistent with a compensatory model of investment. For this model, $\sigma_{\delta \xi}$ is -.0091 with a standard error about one quarter the size of the parameter. There is, however, a very large difference in the $x^{2}$ statistics that measure the goodness of fit of the model to the sample covariance. Indeed, Hause shows that a purely statistical model of the error process dominates any model with a covariance structure.

Column 8 of Table I summarizes my estimates of a simple model using the sample covariance matrix provided in Hause's paper. The covariance between level and growth components is negative and statistically "significant" (in the sense that the estimate is almost 10 times the asymptotic standard error) as are the estimated variances for level, growth and random error components. A covariance model allowing the error variance to differ from period to period (column 9) provides a somewhat better fit than the second of Hause's models and a substantially better fit than a model with a time-invariant error variance. One can clearly see the large difference between the first period's error and subsequent period's errors which decline slowly consistent with simple autocorrelation, patterns that are reflected in the parameter estimates in Hause's second model. However, the parameter estimates for $\sigma_{\delta}^{2}, \sigma_{\xi}^{2}$ and $\sigma_{\delta \xi}$ are virtually unaffected by 
the change in specifications.

The complex error structure tells us little about the behavior that generated the sample covariance. It can be, as we noted, estimated with a much simpler model (where the error structure is, obviously, equally unrevealing) that is "closer" to the explanatory power of Hause's first model. In this case, the variance components associated with the onthe-job investment model are more precisely estimated (column 9). When we allow for time-varying error variances, the variance in growth rates is substantially higher than in Hause's second model (.003 versus .0018). While the covariance between level and growth components remains about the same $(-.009)$, the correlation between these components declines somewhat.

Reestimating Lillard and Weiss's model, using the sample covariance matrices published with their article, provides a quite different interpretation of their data. Columns 1 and 3 of Table I are reproduced from Lillard and Weiss's Table II. In neither case is the critical parameter, $\sigma_{\delta \xi}$, negative. However, if the models summarized in 1 and 3 are reestimated, columns 2 and 4 , al1 of the parameters are very close to those reported by Lillard and weiss except for $\sigma_{\delta \xi}$ which is now negative. Comparing columns 1 and 2, there are very small differences in the new estimates of $\sigma_{\delta}^{2}, \sigma_{\xi}^{2}, \gamma^{2}$ and $\sigma_{v}^{2}$ and each retains about the same level of "significance" as in the results reported by Lillard and Weiss. However, $\sigma_{\delta \xi}$ changes substantially, from .00101 to -.0006 , and the interpretation of the earnings covariance structure is completely different.

Tt does not matter whether or not autocorrelation is modelled (compare columns 3 and 4 ), $\sigma_{\delta \xi}$ remains negative and from 7.5 to 11 
times its standard error. The Lillard-Weiss data are consistent with a compensatory model of behavior even when the effects of observed characteristics are considered.

Estimates of a model using the Lillard-Weiss data where the errors are drawn from distributions with time-varying variances loosely analogous to Hause's more complex error structure (columns 6, 7 or 9). They are reported in column 5. The parameter estimates of interest do not change much, but remain consistent with a compensatory model and are "significant." This model, based on difference in $x^{2}$ statistics, is a much better fit of the data than either of the models reported in columns 1 and 2 or 3 and 4 . (The $x^{2}$ statistic is 357 with 12 degrees of freedom compared with a $x^{2}$ statistic in the range of 700 with 16 degrees of freedom.)

The estimates of the time-varying errors do not, in contrast to Hause, evidence any easily detected pattern.

I have also estimated a model for the Lillard-Weiss data that allows for time-varying error variances using the logarithm of earnings as the dependent variable, Table II, column 3 . This is comparable to the estimates for $\log$ earnings by Lillard and Weiss which are reproduced as column 1, and is more directly comparable to the Hause estimates. The model in column 3, with an uninformative error structure to be sure, dominates column 1 but the parameter estimates are essentially unchanged from the reestimated Lillard-Weiss model (column 2). Since the signs of the coefficients correspond to those estimated by Lillard and Weiss, the model for $\log$ earnings retains the same general interpretation they suggested. However, the covariance between initial earnings and earnings growth is larger than that estimated by Lillard and Weiss and 
the coefficients differ in relationship to one another. This is important in estimating the "overtaking point." The change in the relationship between the variance component associated with growth and the covariance between growth and initial earnings extends the point of minimum variance, the "crossover" point, from 1.5 years (using Lillard and Weiss's estimates) to seven years (using either column 2 or 3 ).

Hause's data produce a larger correlation between growth and level variance components for log earnings than do Lillard and Weiss's data, -.65 (from column 9 of Table I) versus -.52 (from column 3 of Table II, the reestimated model).

Since the error structure is apparently quite different for the two samples, there is little that can be generalized from efforts to estimate the random component(s) differently. Indeed, as noted, allowing for time-varying error variances for the distributions of the errors produces a pattern with a large first year variance and smaller but declining variances in subsequent years in the Hause data and essentially a U-shaped pattern in the Lillard-Weiss data. However, the covariance structures in both data sets are consistent with a model of compensatory behavior.

\section{Some Further Evidence from the Utah Panel}

The Utah Panel is composed of observations on heads of households from 1850 to 1900 . We have income estimates at five-year intervals and wealth and occupation estimates at ten-year intervals. In addition, we know the age of the household head and when that person "entered" the Utah economy either by migration or by marrying and establishing an independent household. Households migrate into Utah, leave Utah, are created and die during the sample period. Thus, we can compose "panels" 
of from two to ten observations per household head for income and from two to five observations for wealth. The panel sizes range from 10,367 individuals for three consecutive income observations (covering 10 years ! to 218 individuals for eight consecutive income observations (covering 35 years). Panels of this sort will be nested. That is, all persons in a four-consecutive observation panel will also be in a three-consecutive observation panel and so forth. The data are described in greater detail in the accompanying appendix.

Detailed analyses of the coarse structures of income and wealth are found elsewhere (see Kearl and Pope, 1984a, 1984b, and 1985). The general properties of the log income regressions can be seen in the following (estimated from a four-observation panel):

$$
\begin{aligned}
& \ln y=\frac{4.58}{(.069)}+\underset{(003)}{.0613} \mathrm{~A}-\underset{(.00003)}{.00067 \mathrm{~A} 2}+\underset{(.0025)}{.031 \mathrm{~T}}-\underset{(.0034) \mathrm{FB}}{(.011)} \\
& -\underset{(.014)}{.091} \mathrm{R}+\underset{(.023)}{.292} W-\underset{(.016)}{.067} \mathrm{C}+\underset{(.037)}{.049} \mathrm{~S}-\frac{.257}{(.021)} \mathrm{L} \\
& -(.081 Y Y 2-(.253 Y 3-(.020) \quad(.020 Y 4) Y 4 \\
& \mathrm{SE}=.814 \\
& 23044 \text { observations } \\
& \text { mean } \log y, 6.27
\end{aligned}
$$

where $A, T, F B, R, W, C, S$ and $L$ are age, time within the Utah economy, foreign birth, residence in a rural area, white-collar, craft, service and common labor, respectively, and $Y 2, Y 3$, and $Y 4$ are dummy variables for the second, third and fourth observations on the same individual in the panel. The regression is normalized on farmers who live in the "urban" county. (The sample is a pooled set of panels; I have omitted the dummy variables associated with the pooling.)

The data exhibit a pronounced age-income pattern that is concave; income increases at a decreasing rate until age 46 and then declines. 
The foreign born and those living in rural areas have lower incomes than U.S.-born individuals living in the urban area. Those living in the economy for a longer period of time have higher incomes than observationally alike individuals who are more recent immigrants or who formed households later in the half century covered by our data, perhaps reflecting Ricardian-type rents.

Occupations are aggregated into five categories, W, C, S, L and F. The relative effects of a particular are very robust over various samples and specifications: white-collar workers have incomes substantially above farmers while common laborers have incomes substantially below farmers. Those identified as craft workers have incomes a bit below farmers and there is generally no statistical difference between farmers and those identified as working in services.

I do not have data on earnings, only on income. For many in the sample, earnings and income will coincide. However, for others, income will include earnings and returns on capital. Hence, we would expect to have more noise in income than in earnings relative to the compensatory model.

Table III provides estimates of the covariance structure for both $\log$ income and the residuals from the regression of $\log$ income on the observed characteristics of the household head, including a quadratic in age, place of residence, place of birth, time in the Utah economy, and occupation. (Following Lillard and Weiss, I jointly estimated the covariance structure and the parameters associated with observed individual characteristics. The parameter estimates changed very little. Therefore, I concentrate on the covariance structure and the 
parameters for the iointly estimated coarse structure are essentially the same as those noted above and reported elsewhere.?

The estimated variance of the individual level effect is generally about .25 while the variance in growth rates is about .001 . There is a strong negative covariance between individual income levels and growth rates consistent with compensatory behavior on the part of the individuals. This crucial parameter is highly significant in every sample. The correlation between initial income and income growth ranges from -.2 to -.6 . The variance is minimized at three years for the four-observation panel and at eight years for the eight-observation panel. These "overtaking" points appear reasonable although the large difference between the two is puzzling.

Although the samples are nested, they differ considerably in size as individuals are lost to migration, death or our inability to trace them from year to year. Nevertheless, the covariance structure is quite stable across the various samples.

When the effects of observed individual characteristics are swept from log income, the estimated variance of the individual level effect declines by about 40 percent for the two large samples but by a considerably smaller amount for the longer but smaller samples (from about .25 to .19 or by about 25 percent). The decline is to be expected since, for log income, the individual effect picks up the contributions of both observed and unobserved individual characteristics while for the residuals, only the contributions of the unobserved characteristics will matter. The year by year effects (a loose measure of economic growth and price changes) are very small since the estimated error variance is virtually the same for $\log$ income as it is for the residuals. That is, 
virtually all of the explained variance is explained by the observed individual characteristics and very little is explained by the dummy variables associated with the year of observation. The random error variance is about 50 percent of the variance in $10 \mathrm{~g}$ income; about 10 percent of the variance in $\mathrm{log}$ income can be explained by the observed individual characteristics and the remaining 40 percent is explained by the "behavioral" part of the covariance structure.

The variance attributed to growth remains the same for residuals as for log income. However, the covariance between growth and individual level components declines. Nevertheless, it remains highly significant. Because both the individual level component and the covariance between initial income and income growth decline, the correlation between the two remain essentially in the range noted earlier, from -.2 to -.6 .

Table IV provides estimates of the covariance structure when the error variance is not assumed to be drawn from a time-invariant distribution. For the short panels, covering from 10 to 20 years, the estimated error variances exhibit a hump shape, increasing and then declining. For the longer panels, the estimated error variances bounce around without a clear pattern. We do not observe a pattern comparable to that in Hause's data, where the error variance declined with time. In the Lillard-Weiss data, the error variances decline and then increase. In any event, the parameter estimates of the "behavioral" part of the covariance structure are essentially insensitive to the change in specification.

These data, from a very different economy, are strongly consistent with an on-the-job investment model of individual behavior. Indeed, even though the dependent variable is income rather than earnings and, as a 
consequence, there ought to be more variance in the data that is not associated with compensatory choices, the results are stronger than those using contemporary data. We might expect, however, that on-thejob investment was more important in an economy that had limited opportunities for formal education but which had skilled occupations than in a contemporary economy, where formal education is widespread. Hence, the relative importance and significance of the parameter estimates are not surprising but they provide important additional evidence consistent with compensatory behavior and the on-the-job training hypothesis.

Changing Growth Rates

Lillard and Weiss provide some evidence that both the variance in growth rates and the variance in income levels increases with experience. We can directly explore the first possibility by considering a more complex covariance structure where,

(16) $u_{i t}=\delta_{i}+\xi_{j}(t-1)+\alpha_{j}(t-1)^{2}+v_{i t}$.

The model is identified so long as the panel has at least four observations on each individual. The parameters of interest are the covariances between the earnings/income level and the change in the growth rate and between the growth rate and the change in the growth rate.

Table $V$ provides estimates using data from Hause, Li1lard and Weiss and the Utah Panel for this more complex covariance structure. It turns out that while I extended the covariance structure in an effort to capture whatever information was contained in the time-varying error variances, the more complex covariance structure fails to do this and models that allow for time-varying error variances dominate those where 
the innovations are assumed to be drawn from a distribution with constant variance.

Models that allow growth rates to differ through time dominate the covariance models estimated to this point. For Hause's earnings data, $x^{2}$ falls from 94 to 49; for Lillard and Weiss's earnings data, $x^{2}$ falls from 566 to 213; for their residual data, $\chi^{2}$ falls from 357 to 72 ; for the Utah Panel, $x^{2}$ falls from 103 to 16 for a five-observation pane 1 and from 103 to 18 for a six-observation panel.

For every data set, there is a negative covariance between $\xi_{j}$ and $\alpha_{i}$ that is, between the growth rate and the change in the growth rate in earnings or income. Since it is likely that $\alpha_{j}$ has a negative sign (that is, that the life cycle profile is concave), the negative covariance implies that those individuals having high growth rates have a greater rate of decline in those growth rates. Since there is a negative covariance between the level of earnings/income and the growth rate, those with higher initial earnings/income who have lower growth rates should also have growth rates that decline more slowly than those with lower initial earnings. The covariance estimates are consistent with this since the covariance between the earnings/income level and the change in growth rate is positive. Comparable results hold for the Lillard-Weiss and Utah Panel residuals.

Put somewhat differently, the mean life cycle pattern in earnings and income is a composite of individual life cycle profiles where those with higher initial earnings (or income) have a flatter profile while those with lower initial earnings (or income) have a profile that is initially steeper but which is more concave. 
The individual level variance component does not change much with the change in specification. However, for each of the samples, the variance in growth rates is larger with the change in specification (e.g., for Hause's data, the growth variance component increases from .003 to 0.18 ). The covariance between the level and growth components is also substantially larger.

The variance in growth rates is substantially higher than that suggested by previous work. The implied correlations between level and growth components increase for all samples except the Lillard-Weiss log earnings data, providing somewhat stronger evidence of compensatory behavior.

Nothing in the models distinguishing on-the-job investments from other forms of human capital accumulation suggests that on-the-job investments should have higher (or lower) rates of depreciation compared with other kinds of investment. In all three data sets, however, the effects of the substantially larger variance in growth rates across the population are tempered by the greater concavity of the earnings/income profile. This suggests that on-the-job investments depreciate more rapidly than other forms of human capital that individuals bring with them to the workplace.

Conclusions

Data from three very different sources are consistent with a compensatory model of earnings or income differences among individuals. This does not mean, of course, that on-the-job investment and compensatory behavior fully explain the observed variance in earnings or income. A substantial part of the variance is apparently stochastic and another large part can be attributed to individual differences that are 
probably associated with ability. However, individual differences in growth rates and in changes in growth rates are important as well and are consistent with on-the-job investment. The observed consistency is robust to a variety to underlying stochastic processes that may contribute to the observed variance. Moreover, the consistency is robust in samples from different places, periods of time and covering different age spreads among individuals.

It is particularly interesting that we find compensatory behavior where it might be expected, in an economy with little reliance on formal education, and yet where the economy is quite different from a contemporary industrial economy.

We also find that there is good evidence that growth rates vary depending upon both the level of earnings/income and the growth rate itself. Models that allow for growth rates to vary for individuals across time appear to dominate those with simpler covariance structures. In addition, the variance in growth rates across individuals at a moment of time varies a good deal more than simpler models suggest.

It is, of course, not possible to tell if the discounted earnings/income are greater or less with the difference in the concavity of the age-earnings or age-income profile, but the data suggest that there is faster depreciation in capital acquired on the job. 
Ben-Porath, Y. "The Production of Human Capital and the Life Cycle of Earnings," Journal of Folitical Economy, 75, August 1967, pp. $352-65$.

Borjas, G. J. and Jacob Mincer. "The Distribution of Earnings Profiles in Logitudinal Data," in Income Distribution and Economic Inequality, Z. Griliches, K. Krelle, H.J. Krupp and 0. Kyn, eds., Frankfurt/Main: Campus Verlag; New York: Halstad Press, 1978.

Chamberlain, Gary. "Omitted Variable Bias in Panel Data: Estimating the Returns to Schooling," Annales de L'Insee, No. 30, 1978, pp. 49-82.

Hause, John C. "The Fine Structure of Earnings and the On-The-lob Training Hypothesis," Econometrica, 48, No. 4, May 1980, pp. 1013-29.

Hause, John $C$. "The Covariance Structure of Earnings and the On-The-Job Training. Hypothesis," Annals of Economic and Social.

Joreskog, K.G. and D. Sorbom. LISREL, Estimation of Structural Equations Systems by Maxmium Likelihood Methods, Chicago: Internationa 7 Educational Services, 1980.

Kearl, J. R. and Clayne Pope. "Life Cycles in Income and Wealth," NBER Working Paper, March 1983, revised January 1984.

Kearl, J. R. and Clayne Pope. "Economic Mobility in Utah from 1850 to 1900," Working Paper, March 1983, revised Ianuary 1984.

Kearl, J. R. and Clayne Pope. "Unobservable Family and Individual Contributions to the Distributions of Income and Wealth," NBER Working Paper, June 1984.

Lillard, Lee. "Inequality: Earnings versus Human Wealth," American Economic Review, 62, 1977, pp. 42-53.

Lillard, Lee and Yoram Weriss. "Components of Variation in Panel Earnings Data: American Scientists 1960-70," Econometrica, 47, No. 2, March 1979, pp. 437-54.

Mincer, Jacob. "The Distribution of Labor Incomes: A Survey with Special Reference to the Human Capital Approach," Journal of Economic Literature, 1970, pp. 1-26.

Mincer, Jacob. Schooling, Experience and Earnings, New York: Columbia University Press, 1974. 


$$
\begin{aligned}
& \text { LN Earnings }
\end{aligned}
$$

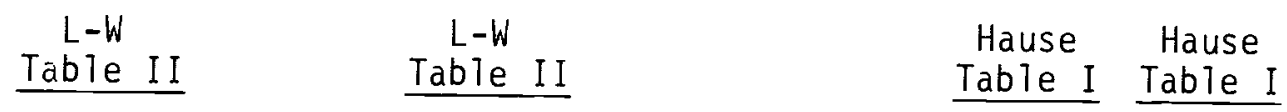

$$
\begin{aligned}
& \begin{array}{lllllllll}
1 & 2 & 3 & 4 & 5 & 6 & 7 & 8 & 9
\end{array} \\
& \begin{array}{llllllllll}
\sigma_{\delta}^{2} & .0321 & (.0030 & .0334 & .0334 & .033 & .027 & .07536 & .067 & .064 \\
& (.00077) & (.0009) & (.00077) & (.0008) & (.0009) & (.021) & (.0121) & (.007) & (.007)
\end{array}
\end{aligned}
$$

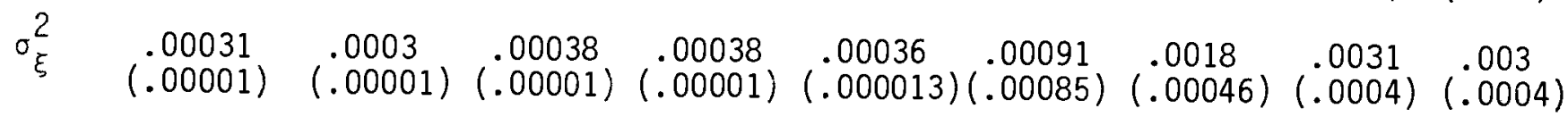

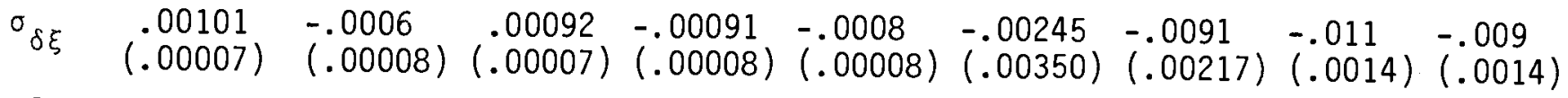

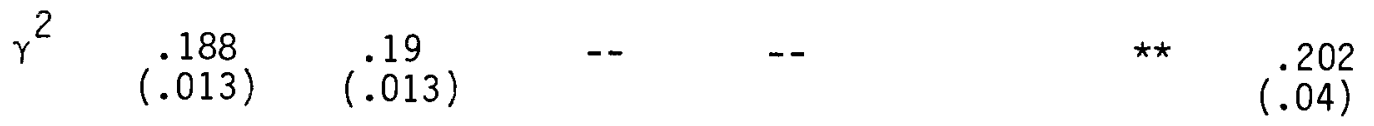

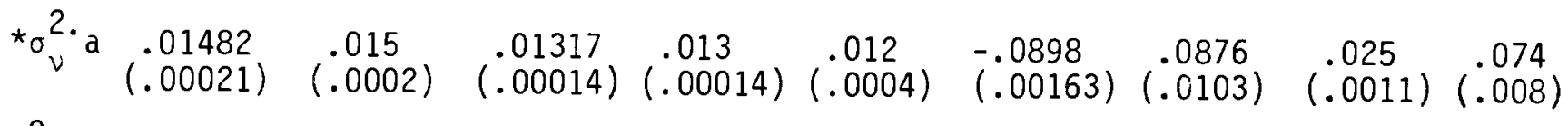

$$
\begin{aligned}
& \sigma_{v_{2}}^{2} \\
& \sigma_{v_{3}}^{2} \\
& \sigma_{v_{4}}^{2} \\
& \sigma_{v_{5}}^{2} \\
& \begin{array}{lll}
.013 & .0498 & .0207 \\
(.0004) & (.0059) & (.0013)
\end{array}
\end{aligned}
$$

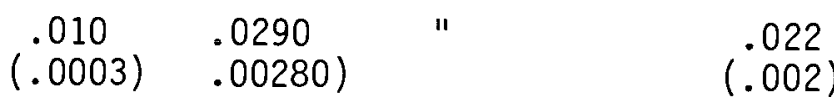

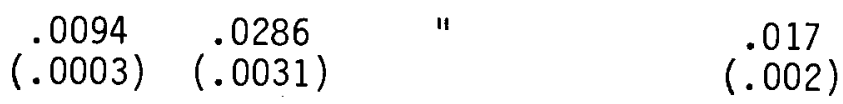

$$
\begin{aligned}
& \begin{array}{llll}
.0165 & .0179 & & 01000 \\
.0005) & (.0042) & .013
\end{array} \\
& \sigma_{v_{6}}^{2} \\
& \begin{array}{lcccc}
\chi^{2} & 746.28 & 720 & 917.6 & 923 \\
\text { df. } & 16 & 16 & 17 & 17 \\
\star_{a}=\left(\frac{1-\gamma^{4}}{1-\gamma^{2}}\right) \text { if } \gamma^{2} \neq 0 \text {, otherwise, } a=1 .
\end{array}
\end{aligned}
$$

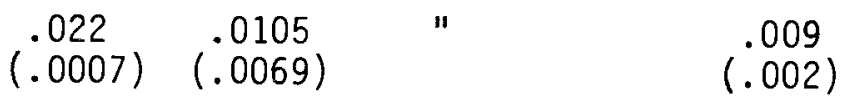

$$
\begin{aligned}
& \begin{array}{lllll}
357 & 7.22 & 111.4 & 290 & 94
\end{array} \\
& \begin{array}{lllll}
12 & 7 & 15 & 17 & 12
\end{array}
\end{aligned}
$$


Ln Earnings

\section{Table II}

$L-W$

$\underline{\text { Table II }}$

\begin{tabular}{|c|c|c|c|}
\hline & 1 & 2 & 3 \\
\hline$\sigma_{\sigma}^{2}$ & $\begin{array}{l}.0617 \\
(.0014)\end{array}$ & $(.085)$ & $\begin{array}{l}.085 \\
(.002)\end{array}$ \\
\hline & $\begin{array}{l}.00049 \\
(.00002)\end{array}$ & $\begin{array}{l}.00055 \\
(.00002)\end{array}$ & $(.0005)$ \\
\hline$\xi$ & $\begin{array}{l}-.00077 \\
(.00011)\end{array}$ & $\begin{array}{l}-.0035 \\
(.00014)\end{array}$ & $\begin{array}{l}-.0034 \\
(.00015)\end{array}$ \\
\hline & $\begin{array}{l}.202 \\
(.014)\end{array}$ & & \\
\hline$v_{v}^{2}$ & $(.015)$ & $(.013)$ & $(.016)$ \\
\hline 2 & & & $(.011)$ \\
\hline 3 & & & $\begin{array}{l}.010 \\
(.0003)\end{array}$ \\
\hline$v_{4}$ & & & $(.007)$ \\
\hline$v_{5}$ & & & $\begin{array}{l}.018 \\
(.0005)\end{array}$ \\
\hline$v_{6}$ & & & $\begin{array}{l}.023 \\
(.0007)\end{array}$ \\
\hline 2 & 1178.2 & 1458.6 & 565.5 \\
\hline & 15 & 17 & 12 \\
\hline
\end{tabular}

Note: Columns 2 and 3 are estimated using the data published in Lillard and Weiss while Column 1 is reproduced from the estimates reported in Lillard and Weiss. 
Ln Income

Table III

Panel Size (\# of observations at 5-year intervals)

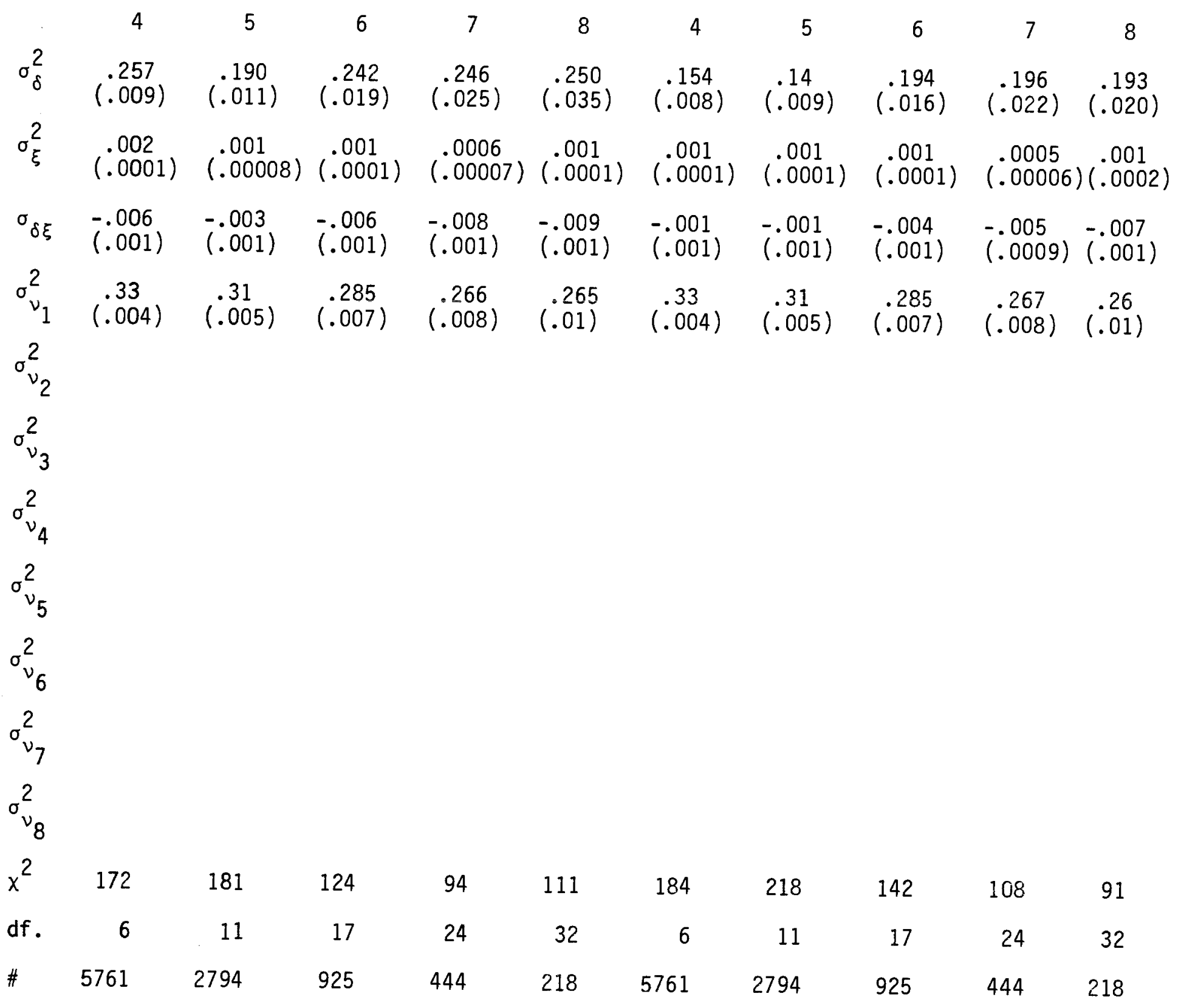


Table IV

Ln Income

Residuals

Panel Size (\# of observations at 5-year intervals)

\begin{tabular}{|c|c|c|c|c|c|c|c|c|c|c|}
\hline & 4 & 5 & 6 & 7 & 8 & 4 & 5 & 6 & 7 & 8 \\
\hline$\sigma^{2}$ & $\begin{array}{l}.245 \\
(.01)\end{array}$ & $\begin{array}{l}.212 \\
(.01)\end{array}$ & $\begin{array}{l}.238 \\
(.019)\end{array}$ & $\begin{array}{l}.232 \\
(.025)\end{array}$ & $\begin{array}{l}.223 \\
(.035)\end{array}$ & $\begin{array}{l}.213 \\
(.009)\end{array}$ & $\begin{array}{l}.163 \\
(.01)\end{array}$ & $\begin{array}{l}.193 \\
(.017)\end{array}$ & $\begin{array}{l}.184 \\
(.022)\end{array}$ & $\begin{array}{l}.195 \\
(.003)\end{array}$ \\
\hline & $\begin{array}{l}.002 \\
(.0001)\end{array}$ & $(.001)$ & $\begin{array}{l}.001 \\
(.0001)\end{array}$ & $(.0006)$ & $\begin{array}{l}.001 \\
(.0001)\end{array}$ & $\begin{array}{l}.001 \\
(.0001)\end{array}$ & $(.001)$ & $(.001)$ & $(.0005)$ & )$(.001)$ \\
\hline & $\begin{array}{l}-.005 \\
(.001)\end{array}$ & $\begin{array}{l}-.005 \\
(.001)\end{array}$ & $\begin{array}{l}-.006 \\
(.001)\end{array}$ & $\begin{array}{l}-.007 \\
(.001)\end{array}$ & $\begin{array}{l}-.008 \\
(.001)\end{array}$ & -.003 & $\begin{array}{l}-.003 \\
(.001)\end{array}$ & $-.004)$ & $\begin{array}{l}-.005 \\
(.00098)\end{array}$ & $-.006)$ \\
\hline & $\begin{array}{l}.24 \\
(.009)\end{array}$ & $\begin{array}{l}.245 \\
(.01)\end{array}$ & $\begin{array}{l}.32 \\
(.02)\end{array}$ & $\begin{array}{l}.30 \\
(.029)\end{array}$ & $\begin{array}{l}.27 \\
(.04)\end{array}$ & $(.24)$ & $\begin{array}{l}.24 \\
(.01)\end{array}$ & $\begin{array}{l}.31 \\
(.02)\end{array}$ & $(.27)$ & $\begin{array}{l}.26 \\
(.04)\end{array}$ \\
\hline & $\begin{array}{l}.33 \\
(.008)\end{array}$ & $\begin{array}{l}.298 \\
(.01)\end{array}$ & $(.27)$ &. .31 & $\begin{array}{l}.35 \\
(.04)\end{array}$ & $\begin{array}{l}.33 \\
(.007)\end{array}$ & $\begin{array}{l}.297 \\
(.009)\end{array}$ & $\begin{array}{l}.28 \\
(.016)\end{array}$ & $\begin{array}{l}.309 \\
(.025)\end{array}$ & $\begin{array}{l}.33 \\
(.04)\end{array}$ \\
\hline & $\begin{array}{l}.39 \\
(.009)\end{array}$ & $\begin{array}{l}.383 \\
(.01)\end{array}$ & $\begin{array}{l}.33 \\
(.02)\end{array}$ & $\begin{array}{l}.31 \\
(.024)\end{array}$ & $\begin{array}{l}.39 \\
(.04)\end{array}$ & $\begin{array}{l}.38 \\
(.009)\end{array}$ & $\begin{array}{l}.387 \\
(.01)\end{array}$ & $(.33)$ & $\begin{array}{l}.325 \\
(.025)\end{array}$ & $\begin{array}{l}.35 \\
(.04)\end{array}$ \\
\hline & $\begin{array}{l}.28 \\
(.012)\end{array}$ & $\begin{array}{l}.323 \\
(.01)\end{array}$ & $\begin{array}{l}.28 \\
(.02)\end{array}$ & $\begin{array}{l}.289 \\
(.02)\end{array}$ & $\begin{array}{l}.29 \\
(.03)\end{array}$ & $\begin{array}{l}.30 \\
(.012)\end{array}$ & $\begin{array}{l}.33 \\
(.01)\end{array}$ & $(.30)$ & $\begin{array}{l}.298 \\
(.022)\end{array}$ & $\begin{array}{l}.29 \\
(.03)\end{array}$ \\
\hline 2 & & $\begin{array}{l}.270 \\
(.01)\end{array}$ & $\begin{array}{l}.25 \\
(.02)\end{array}$ & $\begin{array}{l}.213 \\
(.017)\end{array}$ & $\begin{array}{l}.19 \\
(.02)\end{array}$ & & $\begin{array}{l}.256 \\
(.01)\end{array}$ & $\begin{array}{l}.26 \\
(.015)\end{array}$ & $\begin{array}{l}.219 \\
(.018)\end{array}$ & $\begin{array}{l}.21 \\
(.02)\end{array}$ \\
\hline$\sigma^{2}$ & & & $\begin{array}{l}.25 \\
(.02)\end{array}$ & $\begin{array}{l}.211 \\
(.019)\end{array}$ & $\begin{array}{l}.19 \\
(.03)\end{array}$ & & & $\begin{array}{l}.23 \\
(.017)\end{array}$ & 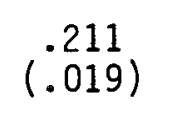 & $\begin{array}{l}.20 \\
(.02)\end{array}$ \\
\hline$\sigma_{v}^{2}$ & & & & $\begin{array}{l}.228 \\
(.024)\end{array}$ & $\begin{array}{l}.19 \\
(.02)\end{array}$ & & & & $(.226)$ & $\begin{array}{l}.21 \\
(.03)\end{array}$ \\
\hline$\sigma_{v_{g}}^{2}$ & & & & & $\begin{array}{l}.26 \\
(.04)\end{array}$ & & & & & $\begin{array}{l}.26 \\
(.04)\end{array}$ \\
\hline$x^{2}$ & 43 & 103 & 103 & 66 & 68 & 44 & 118 & 120 & 79 & 67 \\
\hline$d f$. & 3 & 7 & 12 & 18 & 25 & 3 & 7 & 12 & 18 & 25 \\
\hline & 5761 & 2794 & 925 & 444 & 218 & 5761 & 2794 & 925 & 444 & 218 \\
\hline
\end{tabular}


Táble V

Ln Earnings/Income

Residuals

\begin{tabular}{|c|c|c|c|c|c|c|c|c|c|}
\hline & Hause & $\begin{array}{l}\text { Lillard- } \\
\text { Weiss } \\
\end{array}$ & $\begin{array}{l}\text { Utah } \\
4 \text { obs } \\
\end{array}$ & $\begin{array}{l}\text { Utah } \\
5 \text { obs } \\
\end{array}$ & $\begin{array}{l}\text { Utah } \\
6 \text { obs } \\
\end{array}$ & $\begin{array}{l}\text { Lillard- } \\
\text { Weiss } \\
\end{array}$ & $\begin{array}{l}\text { Utah } \\
4 \text { obs } \\
\end{array}$ & $\begin{array}{l}\text { Utah } \\
5 \text { obs } \\
\end{array}$ & $\begin{array}{l}\text { Utah } \\
6 \text { obs } \\
\end{array}$ \\
\hline$\sigma_{\delta}^{2}$ & $(.069)$ & $\begin{array}{l}.087 \\
(.002)\end{array}$ & $(.274)$ & $\begin{array}{l}.258 \\
(.02)\end{array}$ & $(.258)$ & $\begin{array}{l}.035 \\
(.001)\end{array}$ & $\begin{array}{l}.23 \\
(.02)\end{array}$ & $\begin{array}{l}.20 \\
(.018)\end{array}$ & $\begin{array}{l}.195 \\
(.026)\end{array}$ \\
\hline$\sigma_{\xi}^{2}$ & $(.018)$ & 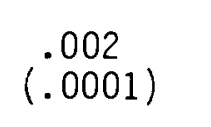 & $(.007)$ & $(.005)$ & $(.0047)$ & $(.00151)$ & $(.007)$ & $(.006)$ & $(.004)$ \\
\hline$\delta \xi$ & $\begin{array}{l}-.0199 \\
(.005)\end{array}$ & $\begin{array}{l}-.0051 \\
(.00035)\end{array}$ & $\begin{array}{l}-.125 \\
(.005)\end{array}$ & $\begin{array}{l}-.0133 \\
(.003)\end{array}$ & $\begin{array}{r}-.0134 \\
(.004)\end{array}$ & $\begin{array}{l}-.0018 \\
(.00025)\end{array}$ & $\begin{array}{l}-.012 \\
(.005)\end{array}$ & $\begin{array}{r}-.0125 \\
(.003)\end{array}$ & $\begin{array}{l}-.009 \\
(.004)\end{array}$ \\
\hline$\alpha$ & $\begin{array}{l}.00047 \\
(.00009)\end{array}$ & 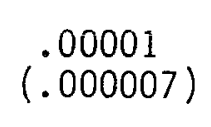 & $(.00002)$ & $(.0 \overline{000 \overline{1}})$ & $(.0000001)$ & )$(.00001)$ & $(.00002$ & $(.00001)$ & $\begin{array}{l}.000006 \\
(.000001)\end{array}$ \\
\hline$\alpha \delta$ & $(.00183$ & $(.0001)$ & $(.00034)$ & $(.00037)$ & $(.00025)$ & $(.00007)$ & $(.0004)$ & $(.00036$ & $(.0002)$ \\
\hline$\alpha \xi$ & $\begin{array}{l}-.00269 \\
(.0006)\end{array}$ & $\begin{array}{l}-.00014 \\
(.00001)\end{array}$ & $\begin{array}{l}-.00034 \\
(.00007)\end{array}$ & $\begin{array}{l}-.00023 \\
(.00003)\end{array}$ & $\begin{array}{l}-.00016 \\
(.00002)\end{array}$ & $-.00011)$ & $\begin{array}{l}-.00034 \\
(.00007)\end{array}$ & $\begin{array}{l}-.00023 \\
(.00003)\end{array}$ & $\begin{array}{l}-.00016 \\
(.00002)\end{array}$ \\
\hline 1 & $(.052)$ & $(.0085)$ & $(.204)$ & $\begin{array}{l}.19 \\
(.02)\end{array}$ & $\begin{array}{l}.26 \\
(.03)\end{array}$ & $\begin{array}{l}.007 \\
(.0006)\end{array}$ & $\begin{array}{l}.193 \\
(.02)\end{array}$ & $(.0184)$ & $(.026)$ \\
\hline 2 & $(.029)$ & $(.0017)$ & $\begin{array}{l}.305 \\
(.009)\end{array}$ & $(.28)$ & $\begin{array}{l}.27 \\
(.02)\end{array}$ & $(.013)$ & $(.009)$ & $\begin{array}{l}.278 \\
(.010)\end{array}$ & $(.016)$ \\
\hline$v_{3}$ & $\begin{array}{l}.021 \\
(.002)\end{array}$ & $\begin{array}{l}.009 \\
(.0003)\end{array}$ & $\begin{array}{l}.369 \\
(.010)\end{array}$ & $\begin{array}{l}.34 \\
(.01)\end{array}$ & $\begin{array}{l}.28 \\
(.02)\end{array}$ & $\begin{array}{l}.009 \\
(.0003)\end{array}$ & $\begin{array}{l}.358 \\
(.010)\end{array}$ & $\begin{array}{l}.333 \\
(.012)\end{array}$ & $(.33)$ \\
\hline$v_{4}^{2}$ & $\begin{array}{l}.013 \\
(.002)\end{array}$ & $(.006)$ & $\begin{array}{l}.238 \\
(.029)\end{array}$ & $\begin{array}{l}.31 \\
(.01)\end{array}$ & $\begin{array}{l}.24 \\
(.02)\end{array}$ & $(.008)$ & $\begin{array}{l}.264 \\
(.029)\end{array}$ & $\begin{array}{l}.317 \\
(.012)\end{array}$ & $(.25)$ \\
\hline$v_{5}$ & $(.012)$ & $(.019)$ & & $(.22)$ & $\begin{array}{l}.25 \\
(.02)\end{array}$ & $(.017)$ & & $(.0208)$ & $\begin{array}{l}.26 \\
(.015)\end{array}$ \\
\hline$\sigma_{v_{6}}^{2}$ & $(.003)$ & $(.018)$ & & & $\begin{array}{l}.15 \\
(.03)\end{array}$ & 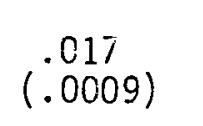 & & & $(.025)$ \\
\hline$x^{2}$ & 49 & 213 & 0 & 17.5 & 18 & 72 & 0 & 19 & 18.7 \\
\hline df. & $\varsigma$ & 9 & 0 & 4 & 9 & 9 & 0 & 4 & 9 \\
\hline$\#$ & 279 & 4330 & 5761 & 2794 & 925 & 4330 & 5761 & 2794 & 925 \\
\hline
\end{tabular}


APPFNDIX

The Utah Panel

Our data are drawn from some or all of the following sources: census manuscripts of $1850,1860,1870,1880$, and 1900; tax assessment records of $1870,1880,1890$, and 1900; financial records of the LDS Church for $1855,1857,1859,1861,1866,1870,1875,1880,1885,1890$, 1895, 1900; and family vital records from the Genealogical Library of the LDS Church.

Estimates of wealth were obtained from the census manuscripts of 1850,1860 , and 1870 and from tax assessment records for 1870,1880 , 1890, and 1900. We sampled from both records in 1870 in order to splice the wealth series from 1850 to 1900 at decade intervals. Both tax assessment and census records provide estimates of gross rather than net wealth.

Income estimates are obtained from the financial records of the LDS Church for the 12 years noted earlier. Essentially we cover five-year intervals from 1855 to 1900 . LDS financial records indicate the contribution an individual made to the Church. Church members accepted the moral obligation to contribute a tithe--ten percent of one's income. In eight of the twelve sample years we have a record of the percentage that an individual's contribution was relative to this full tithe. These assessments of tithing paid versus tithing owed were made by local Church leaders who would personally know the individual contributor. The individual would also be consulted as to the percentage of a full tithe that he or she paid. Families usually made their contribution under the name of the male spouse if there was one although some young men contributed independently to the church. The combination of the 
amount contributed with the percentage of this amount relative to a full tithe yields an estimate of income. We made adjustments for those who reported income in a particular year but for whom we did not have percentages by averaging the percentage paid from other years.

Occupational data have been collected from each census manuscript, available from 1850 to 1900 . Occupations were transcribed into a three-digit code that combined occupations that were essentially the same, e.g., lawyer and attorney. We did not create an occupational status scale. Rather, for purposes of andiysis, these codes were aggregated into four categories: white collar workers, managers, and proprietors (W); farmers, ranchers, dairy owners, etc., (F); craft workers (C); laborers, farm laborers and other unskilled occupations (L). This left a heterogeneous mixture of occupations that were largely service oriented, such as hotel clerks, policemen, lower level clerks, etc., which we classified in a fifth group as service workers (S).

Both census and genealogical records provide place of birth and age. When these sources disagreed, the genealogical record was used. From these two records we could obtain most of the vital statistics of interest, including birth, death, and marriage information, as well as the implied information about household location at particular times, family size and family structure. These records also provide sibling names (linking brothers) and multiple marriage information (linking half brothers).

We used place information to provide a record of residence and internal migration and to provide an estimate of the length of time a household had been within the economy $(T)$. For analysis purposes, we 
consider onty rurat (R) and urban (U) residence where urban is defined as Salt Lake County.

We have 7 inked individuals through time and across records and we have linked these individual histories by family relationship. The core of the sample was created by linking census wealth records using name, location, age, and birthplace data. We then added a random sample of the households from each census year that did not appear in more than one of these censuses. We separately coded links that were "certain" from those for which there were some discrepancies in name spellings or age estimates between census years, "uncertains." We were, however, conservative in our efforts and subsequent analysis has shown no statistically significant differences between "certains" and "uncertains" and hence we no longer carry the coding distinguishing the two. To this core of linked and randomly sampled individuals, we added as many LDS financial records as we could, linked by name across the records and through the years from 1855 to 1900 . We then reversed the procedure: first linking households in the Church financial records and then adding as much census information as was possible.

We added to this sample, now linked through time and between census and church financial records, records from either the censuses or financial records that were potentially fathers and sons. We verified these father-son links using the family vital statistic records from the Genealogical Library. We then searched the family vital statistic records for those in the core sample creating pointers linking those within the sample who were either fathers and sons or brothers. In addition, we added any records from the population data for those we 
could identify as sons or brothers of those in the sample by using the family vital statistic information.

Not all family links between brothers occur with a link to a father. Since we searched the family vital statistic records for those in our sample, we would often find brothers without finding fathers, who might have been dead or who might not have migrated to Utah with their sons. This particular aspect of the sample means that the sibling connections cover the full age range in each year of the sample and are not restricted to be young in the early years. We also found a number of new households that were formed over the fifty-year period where we observed the father for some years and then observed the father and son. Because of the extended period over which we sampled, we also observed fathers and sometimes sons who died and a small group of three generation links.

We added to this linked data additional wealth data from the tax assessments and probates as we11 as occupational data from the 1880 and 1900 censuses. For these records we have neither population data nor random samples from population data. Rather we sought out only those records for individuals already in our sample. Otherwise, however, we have population data for wealth from 1850 to 1870 and income from 1855 to 1900 .

When we added data, anomolies would appear. At each point we purged from the data those links that became questionable with the new information. Obvious checks included: records past death or for an individual who was "too old"; records prior to birth or for an individual who was "too young"; the same name on multiple records from the same source in the same year; substantial age inconsistencies. 
We believe that we have been fairly conservative at each point but we should note that all linking is by names with the attendant problems of misspelling and same names for different individuals. We tried to avoid both problems by not selecting or subsequently eliminating those with common names where the probability was high that there would be several individuals with the same name (e.g., John Jones, James Green). We have differentially coded "certain" family links from those that were "less certain."

The completed data set is essentially a panel, although an individual need not appear in each year either because the individua? migrated in or formed a household later in the period; because the individual migrated out or died during the period; or because we could not make a link in a particular year. It is a panel with the unique characteristic that it is drawn from a fifty-year history of an economy and that it has immediate family links. 